\title{
Construction of the Joint Prevention and Control Management System in the General Ward under Corona Virus Disease 2019
}

\author{
SHU FANG HUANG, L. CHEN ${ }^{1}$, Y. HU, JIE MEI TANG² AND BI XIA ZHAO ${ }^{1 *}$ \\ Department of Gastroenterology, The Affiliated Nanhua Hospital, University of South China, Hengyang, Hunan 421002, \\ China; ${ }^{1}$ Department of Nursing, The Affiliated Nanhua Hospital, University of South China, Hengyang, Hunan 421002, China; \\ ${ }^{2}$ Department of Neurology, The Affiliated Nanhua Hospital, University of South China, Hengyang, Hunan 421002, China
}

Huang et al.: Construction of the Joint Prevention and Control Management System under COVID-19

\begin{abstract}
To investigate how to strengthen the joint prevention and control in the general ward, and to reduce the infection rates of the medical staff and hospital common patients, and reduce the imported infectious cases during the Corona Virus Disease 2019. Then provides a reference for the establishment of the optimal prevention and control system in the general ward except for the infection ward. Combined with the working characteristics of the general ward, the gastroenterology specialty ward was used as the pilot ward. A set of integrated joint prevention and control management system was formed through the health education, closed management of the department, strengthen the management of the staff inside the department, standardize the work requirements of the department during the epidemic situation, and established a contingency plan for the epidemic prevention and control of the special events. After determining the actual operation effect of the joint prevention and control management system, it was promoted to the whole hospital. During the outbreak of Corona Virus Disease 2019, the joint prevention and control management system was used in the gastroenterology specialty ward. None of the hospitalized patients in the digestive specialty ward were suspected or confirmed to have Corona Virus Disease 2019. The average satisfaction of the inpatients was 98.5 points, and the average hospital $d$ was shortened by $1.2 \mathrm{~d}$. After the system was extended to the whole hospital, there were no nosocomial infections among the medical staff in the hospital, including the doctors, nurses, logistics personnel, and the general ward patients, and the ward work proceeded smoothly. The joint prevention and control management system used in the general ward was effective and worth popularizing during the epidemic period.
\end{abstract}

Key words: Corona Virus Disease 2019; General ward; Hospital infection; Joint prevention and control

Corona Virus Disease 2019 (COVID-19) caused by the novel coronavirus has caused a global pandemic ${ }^{[1]}$. The latest data showed that there were more than 4.254 million people diagnosed COVID-19 worldwide until May 13, and more than 291000 deaths. Among them, more than 1.36 million people diagnosed and more than 82000 deaths in the United States, which was the country with the largest number of diagnosed cases and deaths in the world ${ }^{[2]}$. The hospital was the main place to deal with the epidemic, and the control of the nosocomial infection not only requires the efforts of the infection department, but also requires the efforts of the general wards, which were also the high-risk areas. The medical workers were successively infected by the novel coronavirus in the areas affected by the epidemic ${ }^{[3]}$.
According to the report of the Chinese Center for Disease Control and Prevention, until February 11, 2020, in 422 medical institutions providing diagnosis and treatment services for COVID-19 patients in China, about 3019 medical workers had been infected with the novel coronavirus, resulting in 5 deaths $^{[4]}$. Among these nosocomial infection cases, most of them were caused by the lack of protective measures in the early stage of the epidemic, lead to the basic reproductive number (R0) of COVID-19 reached 2.2 $2^{[5]}$. Therefore, it is particularly important to implement the joint prevention and control management of epidemic situation among the departments of the hospital.

During the outbreak of the epidemic in China, our hospital, as one of the designated hospitals for

*Address for correspondence

E-mail: miaotang50904@163.com

Special Issue 7, 2020

Indian Journal of Pharmaceutical Sciences 
COVID-19 patients in Hengyang City, Hunan Province, was responsible for the diagnosis and treatment of a large number of confirmed and suspected patients in the city. According to the national, provincial, and municipal requirements for the joint prevention and control under the COVID-19 epidemic, our hospital responded quickly and asked all the general wards to strengthen the joint prevention and control to achieve zero infection in the hospital. However, because COVID-19 was a new type of sudden and serious infectious disease, there was no effective experience and system to follow. Therefore, we make full use of professional advantages, take the department of gastroenterology as a pilot to formulate the epidemic prevention and control programs to the characteristics of COVID-19 and general ward, according to the Law of the people's Republic of China on the Prevention and treatment of Infectious Diseases, the relevant norms and standards issued by the National Health Commission, and combined with the existing epidemic situation and awareness of the infectious diseases. To ensure the smooth development of the clinical work under the epidemic situation, it was expected to build a joint prevention and control system in the general ward, to reduce the infection of the medical staff, ordinary patients in hospital, and reduce the imported infectious cases. Then, it can provide a reference for the formulation of the optimal prevention and control system for the general ward except for the infection ward at the basic level.

\section{MATERIALS AND METHODS}

\section{Construction of the Integrated and Coordinated Joint Prevention System:}

\section{Hospital background:}

Our hospital is a national Grade 3A general hospital. The department of gastroenterology is a key discipline of the hospital. There is 42 medical staff, including 14 doctors and 28 nurses. At present, there are two wards with 114 hospital beds open.

\section{Health education of the medical staff:}

Strengthening training of the medical staff. The hospital quickly mobilized all the medical staff and set up COVID-19 prevention and control team to be responsible for the rapid deployment and orderly promotion of all kinds of work. Hold a special meeting on the epidemic prevention and control to publicize the current situation of the epidemic to the staff of the department to ensure that everyone pays enough attention to the prevention and control work, and do a good job of personal protection at the same time. Develop different training contents for staff in different positions, and strengthen training for the medical staff on COVID-19 epidemiological characteristics, medical history collection, diagnostic criteria, treatment principles, reporting of the diagnosed patients, and isolation process ${ }^{[6,7]}$. Strengthen the training of the logistics staff in the wearing of protective equipment, daily disinfection, medical waste disposal, and daily life protection.

Health education of the patients and caregivers. Focus on strengthening the education of COVID-19 prevention knowledge, including the transmission route and common symptoms of COVID-19. Instruct the patients and caregivers to wear masks correctly, wash hands frequently, correctly cough, and other personal protection, avoid walking around in the crowded places, avoid visiting the other wards or departments, correctly handle the used masks. Emphasize the current situation of COVID-19 to the patients, required them to selfmonitor their health status, timely report the suspected COVID-19 symptoms, and obtain the cooperation of the patients and caregivers to the work of medical staff during the epidemic.

\section{Closed management of the department:}

The ward was a place where personnel gather. In order to avoid the imported infection, the department started the closed management during the epidemic, posted notices in the eye-catching areas inside and outside the department, and obtained the understanding of the patients and their families.

The department was managed by a single channel, and other exits were closed, only open the entrance of the department gate, strictly manage the entry and exit of the personnel and goods, disinfect the entrance regularly (spray and disinfect the walls and floors with $2000 \mathrm{mg} / \mathrm{L}$ chlorine-containing disinfectant for $30 \mathrm{~min}$ twice a d), and make a relevant record at the same time.

The WHO recommends homemade bleach solutions of about $2-10 \%$ concentration to clean hard surfaces to clear them of any presence of the novel corona-virus. Cleaning hard surfaces with this solution can disinfect them not just from novel corona-virus but also help prevent flu, food borne illnesses, and more. 
New patients need to improve the body temperature monitoring, goods disinfection, and epidemiological history assessment, and fill in the epidemic report. New patients were placed in a single ward, and then transferred to the general ward after no suspected symptoms.

Do good jobs in the education of the caregivers, issue the record card to the caregiver, and monitor the body temperature. Those who do not have a record card or fever were not allowed to enter the department.

Control the number of family visits, if there are visitors, the department should monitor the body temperature in advance, those with fever forbid visiting, and recording the contact information and detailed address.

All the materials brought into the department were handed over outside the entrance and need to be disinfected inside the department (depending on the type of materials, spray with $2000 \mathrm{mg} / \mathrm{L}$ chlorinecontaining disinfectant or $75 \%$ alcohol liniment for disinfection).

Merely, greater than $60 \%$ of alcohol is effective in destroying the virus as per the renowned scientists across the world.

\section{Strengthen the internal management of the department}

\section{Medical staff management:}

All the medical staff in the department takes the body temperature before the shift every $\mathrm{d}$, record the body temperature data of each person every $d$, isolate the feverish people and observe them closely. During the working period, we should strictly do a good job of personal protection, abide by the rules and regulations of the department, and conscientiously complete personal medical tasks. After work, all personnel were required to do a good job of personal protection, no dine together, going out less, washing hands frequently, ventilating more.

When returning to work at the end of the Spring Festival holiday, we should take the initiative to report the holiday situation. People with a history of epidemic contact must be quarantined and observed at home for $14 \mathrm{~d}$ to confirm that they were not infected before they can return to work.

All medical staff required self-checking their health status, and if there are similar symptoms of COVID-19, they should stop medical work immediately and report to the person in charge of the department prevention and control team, do a good job of self-protection and go to the fever clinic of the hospital. Home isolation or hospitalization according to the relevant examination results, if the medical staff diagnosed as COVID-19, immediately check their recent close contacts, and take necessary medical protection measures for them in accordance with the protection guidelines issued by the National Health Commission ${ }^{[8]}$.

\section{Logistics management:}

The logistics staff of the department includes the cleaning workers, professional caregivers, and transfer workers. On the basis of strengthening personal protection and monitoring of their epidemic situation, the logistics personnel should focus on strengthening the following work management.

Standardize the classification and treatment of medical and domestic waste. If there is a confirmed or suspected COVID-19 patient, all medical and domestic waste should be sealed with a double-layer medical garbage bag. The COVID-19-related wastes were collected and stored in the hospital by special personnel and cars, and transport them to specific garbage dumps for incineration as soon as possible.

Clean and disinfect the environment and goods of the department regularly every $\mathrm{d}$, and strict training on the hand hygiene and disinfectant concentration of the logistics personnel.

Professional caregivers are required to accompany the patients "one-to-one" to avoid cross-infection between patients and departments.

Transfer workers are required to check their body temperature before entering the department and do a good job of personal protection. Materials transferred to the department need to be disinfected and registered.

\section{Management of patients and accompanying family members:}

All wards in the department are managed by access control, and each ward is a management unit. It is forbidden to walk around each other between different wards, and it is strictly forbidden to leave the hospital without permission. In the hospital, all the people are required to wear masks, avoid staying and gathering in the public areas of the department, and clean and disinfect the hands in time after entering and leaving the ward. 
Warm reminders and visiting system during the epidemic situation were posted in the ward. Try to reduce the number of caregivers in the ward; do not leave caregivers when the patient's condition and physical condition permit. If the patient needs a caregiver, leave at most one family member as a fixed companion, and may not be replaced at will. For the patients with unaccompanied personnel, it is suggested that they should communicate with their families through the network to avoid fear and loneliness, and the medical staff in the department should pay close attention to the psychological status of the patients.

\section{Standardize the work requirements of departments during the epidemic period:}

The department carries on the online shift to the fever patients every $\mathrm{d}$ and reports to the medical department before 9 o'clock, and requiring everyone to know the fever patients and their causes, and to establish a follow-up management registration form for the fever patients (TABLE 1). The epidemic history of patients with fever, the time and temperature of the first fever, the daily changes of body temperature, and the results of various examinations were recorded.

Check and register the body temperature of all patients and caregivers in the hospital (In addition to the doctor's orders, monitor once a $\mathrm{d}$ in the morning and evening).

Do a good job of the window opening, ventilation, and registration in the ward (twice/d, $30 \mathrm{~min} /$ time)

Wipe and disinfect the surfaces of the ward regularly, and register the environmental disinfection of the ward (spray with $2000 \mathrm{mg} / \mathrm{L}$ chlorine-containing disinfectant or $75 \%$ alcohol liniment for disinfection). The nurses supervise and instruct all patients and caregivers to wear the masks correctly.

Strengthen the study of the latest guidelines for epidemic prevention and control, and build a solid line of defense in theory and practice.

Strictly implement the various regulations and measures, synchronize the latest work arrangements for epidemic prevention and control by the superiors, and make continuous improvements.

\section{Improving the handling of special cases of epidemic prevention and control:}

Make the contingency plans for people with COVID-19 symptoms to prevent transmission in the hospital and enable patients to get treatment as soon as possible (fig. 1).

Set up the emergency isolation ward ${ }^{[9]}$ (close doors, windows, and central air conditioning) in the department, and be equipped with protective equipment (mask, protective clothing, disinfectant, gloves) to ensure the emergency use.

Clinical medical staff found that the patients or caregivers have suspected COVID-19 (combined with epidemiological history and clinical manifestations) ${ }^{[10]}$, or the patients and caregivers take the initiative to report their own suspected symptoms of COVID-19, they should immediately place the patient in the isolation ward to reduce exposure.

After isolating the suspected patient from other patients, the first discoverer should report to the director of the department immediately, the head nurse and the department prevention and control team to coordinate the deployment of emergency response work.

The COVID-19 prevention and control team of the department evaluated the patient's condition again, and immediately asked the hospital COVID-19 expert group for consultation after it was diagnosed COVID-19. Carry out the investigation and isolation treatment of the suspected patients in accordance with the opinions of the expert group.

For the suspected patients, start the work plan for the prevention and control of the epidemic situation of COVID-19 patients in the hospital, and report to the medical department, nursing department, hospital infection department, to achieve secondary protection. Under the guidance of experts, the patients were safely transferred to the special departments through special

TABLE 1: THE FOLLOW-UP MANAGEMENT REGISTRATION FORM FOR THE FEVER PATIENTS

\begin{tabular}{|c|c|c|c|c|c|}
\hline \multirow{2}{*}{ Name } & \multirow{2}{*}{$\begin{array}{l}\text { History of } \\
\text { Epidemiolog }\end{array}$} & \multirow{2}{*}{$\begin{array}{l}\text { The first fever } \\
\text { date/ } \square\end{array}$} & \multirow{2}{*}{ Pathogeny } & \multicolumn{2}{|l|}{$\begin{array}{c}\text { Daily temperature (primary } \\
\text { nurse) }\end{array}$} \\
\hline & & & & Time & Various examinations \\
\hline
\end{tabular}


channels, the goods used by the patients and the ward was finally disinfected, and the patients and the close contacts of the suspected patients in the same ward were isolated and observed.

For patients with the exclusion of COVID-19, the previous treatment regimen should be continued according to ordinary patients.

\section{The operation effect of the joint prevention and} control management system:

Since the outbreak of the COVID-19 epidemic, the department of gastroenterology has started the joint prevention and control management system as a pilot project. From January 1, 2020 to April 15, 2020 a total of 867 patients were admitted to the department of gastroenterology, including 11 patients with a history of direct or indirect contact with epidemic areas, 2 suspected patients, and 0 confirmed patients. Twenty patients with fever (12 males and 8 females, aged 35-75 y) were closely observed after the fever was detected for the first time. Two suspected patients were excluded from the COVID-19 virus infection after the isolation in the emergency ward, consultation of the experts, detection of the throat swab nucleic acid test, and CT examination. The rest of the patients with fever had no history of contact with the epidemic area, and were confirmed to be fever caused by non-COVID-19 virus after serological examination, CT detection, antibiotic treatment, and body temperature monitoring. The average hospital stay of patients was $9.6 \mathrm{~d}$, which decreased compared with the same period last y (10.8 d). Through the questionnaire survey of inpatients' satisfaction in the department of gastroenterology, the average score of patient satisfaction was 98.5, which was higher than that of 95.7 in the same period last $y$.

One medical worker who returned to hospital during

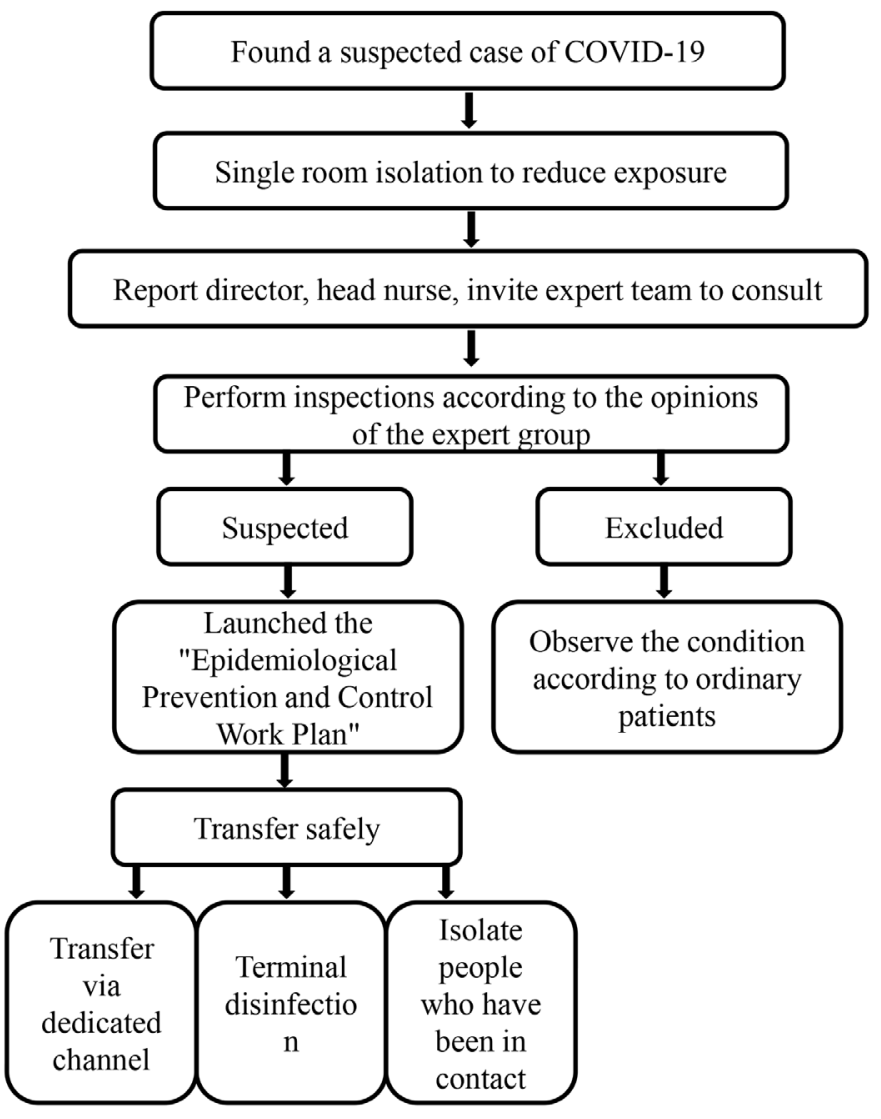

Fig. 1: Emergency plan for people who found symptoms of COVID-19

TABLE 2: RELEVANT DATA ON THE COVID-19 EPIDEMIC PREVENTION AND CONTROL (PERSON)*

\begin{tabular}{lccccc}
\hline & Total & Contact history of epidemic & Fever & Suspected & Diagnosed \\
\hline Inpatients & 867 & 11 & 20 & 2 & 0 \\
Medical staff & 42 & 1 & 0 & 0 & 0 \\
Logistics staff & 6 & 0 & 0 & 0 & 0 \\
\hline
\end{tabular}

*Statistical time: 1 January 2020-15 April 2020 
the Spring Festival holiday had a history of contact with the epidemic area. After self-isolation and observation at home, it was confirmed that he was not infected with COVID-19. There are no suspected or diagnosed patients in the logistics staff (TABLE 2).

Up to April 15, 2020 there were 110 patients in the department of gastroenterology, 42 medical staff on duty, 1 doctor in the isolation ward, 6 doctors in the fever clinic and 2 nurses. Among all medical staff, logistics staff, inpatients, and family members, there were 0 suspected COVID-19 patients and 0 confirmed COVID-19 patients. All the work in the department was in good order, and no cases of imported infection and nosocomial infection of medical staff were found.

After taking the department of gastroenterology as a pilot project to complete the capital construction of the joint prevention and control management system of COVID-19 epidemic situation, and observing the preliminary results, the medical department, nursing department, and hospital infection department of our hospital systematically summarized and analyzed the joint prevention and control management system of the epidemic situation in the department of gastroenterology, and then popularized and applied to the other common wards through a variety of ways (online platform such as hospital website, Wechat, and QQ; offline approaches such as learning meetings for department directors and head nurses). As of April 15, 2020 the infection department of our hospital summarizes and reports the data reported by each department. Since the outbreak of the epidemic in our hospital, the medical staff, the logistics staff of the department and the patients in the general ward had reached zero infection in the hospital, the work of the ward was carried out smoothly.

\section{RESULT AND DISCUSSION}

To sum up, in this COVID-19 epidemic, our hospital took the department of gastroenterology as a pilot project, combined with the working characteristics of the general ward and the transmission characteristics of COVID-19, and established a complete ward joint prevention and control management system from the aspects of strengthening the management of health education, implementing closed management in the department, strengthening the management of internal staff in the department, and improving the handling of special events of epidemic prevention and control.

Since the operation of the joint prevention and control management system in the department of gastroenterology, due to the sufficient health education and training in the early stage, the medical staff have found 20 fever patients in time, and distinguish suspected COVID-19 patients from the ordinary fever patients through evaluation, so that the suspected patients can get further diagnosis and treatment in time. Through the emergency plan made in advance by the department, the two suspected patients identified by the preliminary evaluation of the department all ruled out COVID-19 infection after the individual isolation, expert consultation, temperature monitoring, auxiliary examination, which not only ensured the scientific rigor in the process of diagnosis and treatment, but also avoided the waste of medical resources. The department strengthens the management of medical staff, logistics personnel, patients, and family members and restricts the flow of personnel, which not only ensures their health, but also blocks the possible route of transmission of the epidemic. Standardize the work requirements of the department during the epidemic, so that the work of the department is carried out methodically, and improve the satisfaction of inpatients at the same time. The practice has proved that the joint prevention and control management system established by the department of gastroenterology has significant practical value in the epidemic situation of COVID-19. After being extended to other general wards of our hospital, the integrated joint prevention and control management of general wards has been realized, and no cases of imported infection and nosocomial infection have been found, and the epidemic prevention and control work in our hospital has also been affirmed by the relevant health management departments of the city. And they encourage the other grass-roots hospitals to learn from our hospital. The practice has proved that during the epidemic period in our hospital, the joint prevention and control management scheme in general ward is effective, which is worth popularizing.

COVID-19 epidemic is a major public health emergency related to the life and health of the people, but at present, we know little about COVID-19, and the treatment is still in the research stage ${ }^{[11]}$. Therefore, strengthening the prevention and control of COVID-19 is one of the most effective countermeasures at present. As a general ward, although the patients received are not the patients with fever and pneumonia, the scientific and effective construction of joint prevention mechanism can prevent the nosocomial infection of COVID-19, ensure the smooth development of the work of medical 
staff, improve the satisfaction of inpatients, and protect the life and health safety of patients, family members, and medical staff.

\section{Acknowledgments:}

This work was supported by the Construction and practice of five-level control system for nursing quality management based on 6S management model (No. 2019YYGL03)

\section{Conflict of Interests:}

The authors declared no conflict of interest.

\section{REFERENCES}

1. Gong G, Wang L, Wu Z. Research Progress of Novel Coronavirus SARS-CoV-2. Nat Sci 2020:1-8.

2. Xinhua net. Global epidemic briefing: the press secretary of the Russian president confirmed infected with SARS-CoV-2, and the number of aggregated infections in South Korea was over 100. 2020

3. Lei H, Ding L. Challenges and reflections of COVID-19 on modern nosocomial infection management. Chin J Hosp Infect 2020:1-5.

4. Epidemiology Working Group for NCIP Epidemic Response. The epidemiological characteristics of an outbreak of 2019 novel coronavirus diseases (COVID-19) in China. Chin J Epidemiol 2020,41:145-51.

5. Qun L, Xuhua G, Peng W, Xiaoye W, Lei Z, Yeqing T, et al.
Early Transmission Dynamics in Wuhan, China, of Novel Coronavirus-Infected Pneumonia. N Engl J Med 2020; 382:1199-207.

6. Huang C, Wang Y, Li X, Ren L, Zhao J, Hu Y, et al. Clinical features of patients infected with 2019 novel coronavirus in Wuhan, China. Lancet 2020;395:497-506.

7. Wang D, Hu B, Hu C, Zhu F, Liu X, Zhang J, et al. Clinical Characteristics of 138 Hospitalized Patients With 2019 Novel Coronavirus-Infected Pneumonia in Wuhan, China. JAMA 2020;323:1061-9.

8. Diagnosis and Treatment Protocol for COVID-19. National Health Commission of the People's Republic of China 2020.

9. Longmin D. Prevention implementation and management of technical specifications and standards for hospital isolation. Chin J Disinfect 2015;32:261-4.

10. Jin YH, Cai L, Cheng ZS, Cheng H, Deng T, Fan YP, et al. A rapid advice guideline for the diagnosis and treatment of 2019 novel coronavirus (2019-nCoV) infected pneumonia (standard version). Mil Med Res 2020;7:4.

11. Shen Q, Wang J, Yang S, Xiaochun W, Wen Z. The key scientific problems to be clarified in the New Coronavirus SARS-CoV-2. Journal of Jiangsu University (Med Sci) 2020:1-7.

This is an open access article distributed under the terms of the Creative Commons Attribution-NonCommercial-ShareAlike 3.0 License, which allows others to remix, tweak, and build upon the work non-commercially, as long as the author is credited and the new creations are licensed under the identical terms

This article was originally published in a special issue, "Biomedical Research in Clinical and Preclinical Pharmaceutics" Indian J Pharm Sci 2020:82(5)Spl issue7;87-93 